Professor Dumitru MIRON, PhD

E-mail: dumitru.miron@ rei.ase.ro

Lecturer Radu Cezar COJOCARIU, PhD

E-mail: cezar.cojocariu@gmail.com

Associate Professor Anca TAMAŞ, PhD

E-mail: anca.tamas@ rei.ase.ro

The Bucharest University of Economic Studies

\title{
USING GRAVITY MODEL TO ANALYZE ROMANIAN TRADE FLOWS BETWEEN 2001 AND 2015
}

\begin{abstract}
The main aim of the paper is to analyse the factors which influence the dimension, dispersion and the level of efficiency of Romania's trade flows in the 2001-2015 period. We have conducted a statistical analysis using EViews, which employed the Panel Least Squared method and the Estimated Generalized Least Squared method. We also provided a critical review of the literature covering the gravity model. Some of the questions we touch upon in this paper are: the variables for similarity as predictors of trade flows, the matrix which synthesizes the differences between potential and actual trade flows and the magnitude of convergence at trade flow level. We focused our discussion on the trade flows between Romania and specific countries for a period which stretches for fifteen years. Our primary scientific goal was to provide an overview of Romanian's recent trade flows and to propose some new predictors for the international flows of goods and services. We want to point out that the conclusions which stem from our empirical study are contingent on the relatively short period we examined and that future research may be considered extending the reference period in order to refine the results of the gravity model further.
\end{abstract}

Keywords: Romanian trade flows, potential trade, actual trade, convergence, gravity model, similarity.

\section{JEL Classification: F14 Empirical Studies of Trade}

\section{Introduction}

The gravity model could be considered a successful empirical model if one takes into account its extensive use in the field of applied economics, especially when it comes to analyzing trade flows. However, despite its relatively wide use, based on its predictive power, the model still lacks a comprehensive theoretical 
backing, in the sense that it is strangely cut off from any reference to acting individuals. But, what the gravity model appears to be lacking in theoretical rigor, it supposedly makes up for through sheer practical results.

The epistemological base for the gravity model was Newton's law of gravitation, which states that "every two particles attract one another with a force that is proportional to the product of their masses and inversely proportional to the square of the distance between them" (Encyclopedia 2, 2015).

$f_{i j=a} \frac{m_{i} \cdot m_{j}}{d_{i j}^{2}}(1)$, where $f_{i j}$ represents the attraction forces, $\mathrm{m}_{\mathrm{i}}$ and $\mathrm{m}_{\mathrm{j}}$ are the masses of the two particles, $\mathrm{d}_{\mathrm{ij}}{ }^{2}$ is the square of the distance between the particles.

Mutatis mutandis, applied economists, transposed these insights provided by physics, a natural science, into the field of international exchange and gave them the following reinterpretation: The bigger the "size" of two national economies and the smaller the "distance" that separates them, the larger the trade flows that are going to take place between them.

The paper is structured in six sections. First, we will provide a bird's-eye view of the relevant literature, to see how the gravity model has evolved. We will briefly touch upon some refinements that the model underwent, for example how nil values for trade flows should be taken into consideration and what variables have been incorporated in the model by different authors. In the sections two and three, we will outline our model and provide a short description of the variables that went into its elaboration. Here, we also present the hypothesis that we are going to test with the help of our gravity model. In sections four and five, we provide a statistical description of the data that was used, turning then to a synthetic presentation of the findings that resulted after running the panel regression. In the sixth section, we attempt to draw some practical implications of our model by examining the efficiency and the speed of convergence of Romania's actual trade flows vis à vis its potential trade flows, i.e., the values obtained after running the regression. In this section, we also provide a brief discussion on how policymakers can use the gravity model as a tool for prioritizing trade liberalization. The final section concludes by reviewing which of our five hypotheses have been confirmed.

\section{Literature review}

In 1962, the Nobel laureate Jan Tinbergen performed the gravity model to predict trade flows trends. Tinbergen substituted the particles used by physicists in the original formulation of the law of gravity with two countries and the forces that develop between them with international trade flows. The masses of the particles were taken to be the size of the economies of the countries under consideration, 
while the distance between them was accounted for by the mileage that separated the respective national territories.

In the relation used by Tinbergen, the independent variables are GDP for both countries, the bilateral distance between countries and three dummy variables, namely, sharing a common border and the membership in two free trade agreements - the Commonwealth and the BENELUX (Tinbergen, 1962).

For the gravity models, relation (1) becomes $f_{i j=} \frac{m_{i}^{\alpha_{i}} \cdot m_{j}^{\alpha_{j}}}{d_{i j}^{\beta_{i j}}}$ (2). If $\ln$ is applied to relation (2), the general form for the gravity model becomes:

$\ln f i j=\ln a+\alpha_{i} \ln m_{i}+\alpha_{j} \ln m_{j}-\beta_{i j} \ln d_{i j}+\varepsilon$

The traditional gravity model uses a relation that links through a regression function the logarithm of bilateral trade values, which represents the dependent variable, with three independent variables: $\log$ of GDP, the $\log$ of population figures (each of them for origin and destination country), and the log of the bilateral distance.

Also, the classical model uses another regression function to calculate the potential trade flows, in order to compare the values predicted by the model with actual trade flow figures. The formula is:

Ln (potential trade flows) $=a_{0}+a_{1} \ln ($ economy size for origin country) + $a_{2} \ln \left(\right.$ economy size for destination country) $+a_{3} \ln ($ market size for origin country) + $a_{4} \ln$ (market size for destination country) $+a_{5} \ln$ (distance between the two countries)+ error factor.

Therefore, the equivalent of the mass variables are the size of the economy, regularly measured by gross domestic product (GDP) and the market size, usually measured by population size. The estimated coefficients are normally close to 1 , yet the methods that are used for analyzing bilateral trade do not require this assumption (Feenstra, 2002). Therefore it is not unusual to obtain values ranging anywhere between 0.7 and 1.1. Note that the theory used to derive the gravity equation predicts coefficients of one, while interpretations for those instances in which coefficients differ from one seem to be lacking.

Distance is almost always measured using the "great circle" formula. This formula approximates the shape of the earth as a sphere and calculates the minimum distance along the surface. Why does distance matter so much? Because distance is a proxy for transport costs and for transport time and also involves accidental damages, spoiling or loss during transportation (Head, 2003). Of course, 
the fact that distance is approximated by the span between the capital cities of the countries under consideration cannot account for those cases in which the localization of the metropolis is closer to one of the borders. For example, in the case of Romania, the distance between Bucharest and the country's southern border is considerably shorter than the length of the space between the capital and the northern border. Also, in the rare cases of city-states, like Hong Kong, the distance taken into account receives the same treatment as in the case of the Russian Federation, although the distance between Moscow and Pevek, the country's northernmost town, is considerable.

The seminal work of Tinbergen was developed by Linnemann (1966). He used the gravity model in extensive empirical studies and stressed some econometric problems of the model, particularly how should "the zeros" (no trade between some pairs of countries) be taken into consideration. Another problem that Linnemann's work has addressed is how to take into account those instances where there are several economic centers that can be found in the territory of a single country, in order to obtain a more relevant measure of the bilateral distance between national economies.

Particularly in the " $70 \mathrm{~s}$, economists have tried to provide a more solid theoretical background for the gravity model. Empirical studies proved that the importer's GDP plays an important role to increase the trade and the bilateral exchange rate has no influence on the trade (Anderson, 1979).

Subsequent studies, like the one conducted by Aitken (1973), analyzed the effects on trade flows entailed by a country's membership in a regional trade agreement, like the European Economic Community and the European Free Trade Agreement. Sapir (1981) did the same for the Generalized System of Preferences (GSP). Both studies reached the conclusion that regional trade agreements have a significant influence on trade flows.

Authors such as Anderson (1979), asserted that the gravity model is the equivalent of four-equation partial equilibrium model of export supply and import demand, but in a more condensed form. One needs to mention that the traditional gravity model has interesting practical implications: large national economies have a higher share of global international flows, small economies are more open to trade and have a higher level of economic freedom, while the degree of economic freedom at international level depends on the number of countries with similar economic size (Anderson, 2011).

When considering the econometrics behind the gravity model, we must point out that some issues were raised by the use of log-linearizing in the 
multiplicative gravity equation, which is estimated using ordinary least square under the homoscedasticity assumption. Reservations pertaining to this method have been expressed by Santos Silva and Tenreyro (2006). The aforementioned concerns lead to proposals for using non-linear estimators instead.

Another controversy raised around the gravity model regarded the zero value trade flows, namely how to treat those situations in which the values of both imports and exports were zero. Curiously, attempts to use the gravity model for a more nuanced approach, i.e., one that distinguishes between the types of goods that comprise international trade flows, have been relatively rare.Also, recent technological and regulatory developments have made possible and stimulated the international supply of services. When it comes to this relatively recent development that affects the structure of international trade, it must be emphasized that the geographical distance is consistently more important for trade in services (exports and imports) than for trade in goods.

A relatively recent contribution by Egger (2002) introduced a new independent variable for the gravity model, called Similar. As we will see in the following section, we will build on Egger's contribution by introducing in our model two variables whose purpose is to capture the degree in which partner countries have a similar level of economic development, respectively a similar population size. These are two complementary variable, they don't replace the classical GDP and population size variables. For the moment, let us see how Egger's Similar is calculated and how it applies to our study of Romania's trade flows.

Similar $=1-\left(\frac{G D P_{i t}}{G D P_{i t}+G D P_{j}}\right)^{2}-\left(\frac{G D P_{j}}{G D P_{i t}+G D P_{j}}\right)^{2}$, where i refers to the home country, in our case, Romania, $\mathrm{j}$ to a partner country, while $\mathrm{t}$ refers to the time period taken into consideration, which stretches from 2001 to 2015. Similar captures the similarity between the two countries regarding their GDP. Its value is between 0 (perfect difference) and 0.5 (perfect similarity). Usually, countries with similar GDP tend to trade more. That's why, this variable has a positive influence on trade flows, the larger Similar is, the higher the volume of inter-industry and the overall trade will be (Egger, 2002).

Now, after reviewing the literature and after seeing how other authors have accounted for the similarity between countries, let us briefly present the primary hypotheses of our empirical study:

$\mathrm{H}_{1}$ : The economic size has a positive effect on trade flows. 
H2: The similarity between countries in terms of GDPPC and population positively influences the trade flows.

$\mathrm{H}_{3}$ : The geographical distance between countries has an adverse effect on trade flows.

$\mathrm{H}_{4}$ : Sharing a common border, by which we mean EU or Schengen membership, has a positive effect on trade flows.

$\mathrm{H}_{5}$ : The remoteness of partner countries has a negative influence on trade flows

\section{Data and Methodology \\ The model}

In this study, a new model based on the one developed by Egger in 2002 was considered. The log-linear model is:

LnTRADEt $=$ constant $t_{t}+c_{1 t} l n G D P P C T+c_{2 t} \ln$ Simcap $+c_{3 t} \operatorname{lnSimpop}+c_{4 t} \ln$ dist + $c_{5 t} U E+c_{6 t}$ Schengen $+c_{7 t}$ Border $+c_{8 t}$ Lang $+c_{9 t}$ Landlocked $+c_{10 t}$ Islancountries + $\varepsilon_{t}$

Where,

- TRADEt represents the actual bilateral trade flows between Romania and its commercial partners in year $\mathrm{t}$; the zeroes were eliminated, therefore only bilateral trades with both imports and exports, imports only or exports only were included; by bilateral trade between Romania and a partner country, we mean the sum of import and export products for each of the considered years. Lntrade is the dependent variable. Ln TRADEt represents $\ln \mathrm{f}_{\mathrm{ij}}$ from the general gravity model. The data was collected from https://comtrade.un.org/data.

- GDPPCT $_{i}$ is the sum of the GDP per capita figures for Romania and a partner country in year $t$ and it represents a measure of the economic size. $\mathrm{LnGDPPCT}_{\mathrm{i}}$ is an independent variable and represents $\operatorname{lnm}_{\mathrm{i}}$ in the general model. Although the dynamics of exports is related to the dynamics of GDPPC, the variables InTRADE and InGDPPC are not correlated, the Pearson coefficient value is only 0.302 . We expect GDPPCT to have a positive influence on trade flows. The source of the data is https://data.worldbank.org.

- Dist is the distance in $\mathrm{km}$ between the capital of Romania and the capital of a partner country. Data from www.chemical-ecology.net was used. Lndist is an independent variable and represents $\ln \mathrm{d}_{\mathrm{ij}}$ from the general gravity model. We expect Dist will have a negative influence on trade flows.

- Simcap $p_{t}$ is an independent variable, computed with the following formula:

$$
\text { Simcap }_{t}=1-\frac{G D P P C_{p t}^{2}+G D P P C_{r t}^{2}}{\left(G D P P C_{p t}+G D P P C_{r}\right)^{2}}
$$


Where GDPPCpt was the GDP per capita of the partner country in year t, GDPPCrt was the GDP per capita of Romania in year t. Simcapt should have values between 0 and 0.5 , where 0 means that an absolute divergence between Romania and the partner country exists, while a value of 0.5 represents an absolute convergence between Romania and the partner country regarding their GDP per capita. We expect Simcapt to have a positive influence on trade flows.

- Simpopis an independent variable, computed with the following formula:

Simpop $_{t}=1-\frac{P O P_{p t}^{2}+P O P_{r t}^{2}}{\left(P O P_{p t}+P O P_{r}\right)^{2}}$

Where $\mathrm{POP}_{\mathrm{pt}}$ represents the population of the partner country in year $\mathrm{t}$, POP $_{\mathrm{rt}}$ is the population of Romania in year t. Simpop ${ }_{t}$ should result in values between 0 and $0.5,0$ being absolute divergence between Romania and the partner country, while 0.5 means that an absolute convergence between Romania and the partner country exists when it comes to their population. We expect Simpop to have a positive influence on trade flows.

- We anticipate that the coefficients for $\ln$ GDPPCT $_{i}$, ln Simcap, , ln Simpop to be positive, and the coefficient of lndist to be negative, which means that we expect our results to be in line with those produced by previous studies. These variables were expressed in natural logarithms, so coefficients obtained from linear estimation can be read directly as elasticities. The elasticity of trade for distance, for instance, is usually between -0.7 and -1.7 , while elasticity for GDPPC is usually unitary.

- Border is a dichotomic variable that shows if Romania and a partner country have a common border, in which case the value is 1 or don't share a common border, in which case the value is 0 .

- EU is a dichotomic variable, which takes the value 1 if the partner country is an EU member and the value 0 if the partner country is outside the EU member states group.

- Lang is a dichotomic variable, which shows if Romania and a partner country share a common tongue, in which case the value is 1 , otherwise is 0 . The countries with a common tongue with Romania are: Armenia, Australia, Austria, Belgium, Canada, France, Germany, Hungary, Ireland, Italy, Luxembourg, Moldova, New Zeeland, Spain, Switzerland, United Kingdom and United States.

- Schengen is a dichotomic variable that has the value 1 if the partner country is a Schengen member and the value 0 if the partner country is not a Schengen member.

- Landlocked is a dichotomic variable, meaning that it takes the value 1 if the partner country is surrounded by other countries and has no direct 
access to the oceans and 0 if it has some access to sea routes. The data has been collected from https://www.thoughtco.com/geography-4133035.

- Island countries is a dichotomic variable, which takes the value 1 if the partner country is an island and 0 otherwise. The data was collected from https://data.worldbank.org.

- We expect Border, Lang, EU, Schengen to have a positive influence on trade flows, while landlocked and island countries to have a negative influence on trade flows, according to previous studies.

- $\quad \varepsilon_{\mathrm{t}}$ is the error for year $\mathrm{t}$

- $\quad t$ has the values: 2001, 2002, ,.., 2015

- constant; $c_{1 t}, c_{2 t}, c_{3 t}, c_{4 t}, c_{5 t}, c_{6 t}$ are parameters that are going to be estimated using the software EViews $10 \mathrm{SV}$

\section{Sample and data description}

We intended to use a balanced panel in order to obtain more reliable and robust regression outputs. Therefore, from the initial panel of countries, we only kept the ones with all data for each variable, with a total of 2754 observations in all 15 years considered. So, the panel used in the study is balanced, fixed (because all countries were observed at the same time) and short (because the number of countries exceeded the number of years).

First, we address the potential stationary problems, which were tested using the Unit Root Tests available in EViews. Unit Root is used to check if data is stationary or not. Stationary data is important because otherwise spurious results might occur. The results are presented in table 1:

Table 1. Panel Unit Root Tests results

\begin{tabular}{|c|c|c|}
\hline & ADF - Fisher Chi-square & Sig \\
\hline EU & 56.0134 & 0.0000 \\
\hline ISLANDCOUNTRIES & 96.9331 & 0.0000 \\
\hline LANDLOCKED & 94.6338 & 0.0000 \\
\hline LNDIST & 150.698 & 0.0000 \\
\hline LNGDPPCT & 133.323 & 0.0000 \\
\hline LNSIMCAP & 189.160 & 0.0000 \\
\hline LNSIMPOP & 142.754 & 0.0000 \\
\hline
\end{tabular}


Using Gravity Model to Analyze Romanian Trade Flows between 2001 and 2015

\begin{tabular}{|c|c|c|}
\hline LNTRADE & 159.436 & 0.0000 \\
\hline SCHENGEN & 81.1614 & 0.0000 \\
\hline
\end{tabular}

Source: Authors' table based on EViews outputs

To test the unit root, the ADF Fisher Chi-square was used in EViews 10. The output file indicated that the null hypothesis was rejected and, therefore, all variables are stationary at first level.

\section{The Findings}

The panel regression was performed in EViews, first the unrestricted OLS model, using lntrade as the dependent variable. Secondly, we tested the model for fixed effects and random effects, FEM and REM models respectively. The redundant fixed effect tests and the Hausman test were run in order to choose which model would be more consistent, the FEM or the REM. FEM should be chosen if individual effects and explanatory variables are correlated, while REM should be chosen if individual effects are random and they are not correlated with the explanatory variables. After estimating the panel equation, random effects were chosen for the period and then the Hausman test was applied. Since the Sig is less than 0.05 , the FEM is the most appropriate.

Correlated Random Effects - Hausman Test

Equation: Untitled

Test period random effects

\begin{tabular}{lrrr}
\hline \hline Test Summary & Chi-Sq. Statistic & Chi-Sq. d.f. & Prob. \\
\hline \hline Period random & 31.364303 & 6 & 0.0000 \\
\hline \hline
\end{tabular}

The last problem we needed to address was heteroscedasticity. For this we chose the panel EGLS (Estimated Generalized Least Squares) method, comparing cross-section weights, period weights, and cross-section SUR options.

Table 2. Comparative estimates

\begin{tabular}{|l|c|c|c|c|c|}
\hline $\begin{array}{c}\text { Variables } \\
\text { and } \\
\text { statistics }\end{array}$ & $\begin{array}{c}\text { Coefficient } \\
\text { estimates }\end{array}$ & $\begin{array}{c}\text { Unrestricted } \\
\text { OLS } \\
\text { Two-way } \\
\text { random } \\
\text { effects }\end{array}$ & $\begin{array}{c}\text { Panel EGLS } \\
\text { Cross-section } \\
\text { weights }\end{array}$ & $\begin{array}{c}\text { Panel } \\
\text { EGLS } \\
\text { Period } \\
\text { weights }\end{array}$ & $\begin{array}{c}\text { Panel EGLS } \\
\text { Cross-section } \\
\text { SUR }\end{array}$ \\
\hline LNGDPPCT & Coefficient & $1.827902^{* * *}$ & $1.994094^{* * *}$ & $1.946042^{* * *}$ & $1.751805^{* * *}$ \\
\hline LNSIMCAP & Coefficient & $1.372949^{* * *}$ & $1.582275^{* * *}$ & $1.226224^{* * *}$ & $1.225675^{* * *}$ \\
\hline
\end{tabular}


Dumitru Miron, Radu Cezar Cojocariu, Anca Tamaș

\begin{tabular}{|c|c|c|c|c|c|}
\hline LNSIMPOP & Coefficient & $1.411253^{* * *}$ & $1.550506^{* * *}$ & $1.485341^{* * *}$ & $1.433803^{* * *}$ \\
\hline LNDIST & Coefficient & $-0.083238^{*}$ & $-0.094235^{* *}$ & $-0.087707^{* *}$ & $-0.090796^{* * * *}$ \\
\hline LANDLOCKED & Coefficient & -0.709258 & -0.669803 & -0.571452 & $-0.580270^{* * * *}$ \\
\hline $\begin{array}{l}\text { ISLANDCOUNTR } \\
\text { IES }\end{array}$ & Coefficient & -0.333497 & -0.258847 & -0.049698 & -0.034559 \\
\hline BORDER & Coefficient & $\begin{array}{l}3.684785^{* *} \\
(1.514456)\end{array}$ & $3.788163^{* *}$ & $3.640052^{* * *}$ & $3.948105^{* * *}$ \\
\hline LANG & Coefficient & 0.849813 & 0.841114 & 1.031971 & 0.729568 \\
\hline $\mathbf{E U}$ & Coefficient & 0.947749 & 0.710566 & $1.404966^{*}$ & $1.408193^{* *}$ \\
\hline SCHENGEN & Coefficient & 1.103882 & 1.187084 & 1.949490 & $0.665882^{*}$ \\
\hline $\mathrm{C}$ & Coefficient & -2.852170 & $-3.708037^{*}$ & $-3.944814^{*}$ & -2.273452 \\
\hline \multirow[b]{5}{*}{ Statistics } & R-squared & 0.564722 & 0.631088 & 0.637985 & 0.856419 \\
\hline & $\begin{array}{l}\text { Adjusted } \\
\text { R-squared }\end{array}$ & 0.536457 & 0.607133 & 0.614478 & 0.847096 \\
\hline & $\begin{array}{l}\text { S.E. of } \\
\text { regression }\end{array}$ & 2.427542 & 2.427199 & 2.424459 & 1.016299 \\
\hline & F-statistic & 19.97967 & 26.34442 & 27.13972 & 91.85688 \\
\hline & $\begin{array}{l}\text { Prob(F- } \\
\text { statistic) }\end{array}$ & 0.000000 & 0.000000 & 0.000000 & 0.000000 \\
\hline
\end{tabular}

Source: Authors' table based on EViews outputs

Legend: standard errors are shown in brackets, ${ }^{* * *}$ significant at $1 \%,{ }^{* *}$ significant at $5 \%$, "significant at $10 \%$.

The results are robust and statistically significant, the most appropriate model is the one obtained using the Panel EGLS method with the cross-section option. This is due to the fact that it had both the highest F-statistics and the highest Adjusted R-squared among all considered models. The coefficients have the expected signs and their values are in range and line with previous studies, 
except for the ones for distance, which are lower. Among all coefficients, only those for Lang and Island countries are not statistically significant in neither of the considered models, while the coefficients for lnGDPPCT, InSimcap, InSimpop, lnDist and Border are significant in all the considered models. The calculation of the trade variable as the sum between the imports and the exports resulted in a significant improvement of the values of the regression coefficients. A model excluding the variables which were not significant in the Panel EGLS cross section option SUR was tested, but the value of adjusted R squared did not improve, on the contrary, meaning that, even though these variables were not significant, they do have some explanation power on the dependent variable.

Finally, the standardized residuals are normally distributed, as seen in the next table.

Table 3. Normality tests results

\begin{tabular}{|l|l|l|l|l|}
\hline & $\begin{array}{c}\text { Unrestricted } \\
\text { OLS } \\
\text { Two-way } \\
\text { random effects }\end{array}$ & $\begin{array}{c}\text { Panel EGLS } \\
\text { Cross-section } \\
\text { weights }\end{array}$ & $\begin{array}{c}\text { Panel EGLS } \\
\text { Period } \\
\text { weights }\end{array}$ & $\begin{array}{c}\text { Panel EGLS } \\
\text { Cross-section } \\
\text { SUR }\end{array}$ \\
\hline Jarque-Bera & 0.907301 & 0.643949 & & 1.236166 \\
\hline Prob & 0.635305 & 0.724717 & & 0.538977 \\
\hline
\end{tabular}

Source: Authors' table based on Eviews outputs

6. Practical implications: Efficiency and speed of convergence

In order to assess the efficiency of Romania's trade, we computed the difference between the actual trade and the potential trade, by which we mean the values estimated by the model which was analyzed. If this difference is negative, it means that the actual trade is below its potential and the trade is inefficient. If the difference is positive, it means the actual trade is above its potential and the trade is efficient. For the difference, a standard deviation around the mean was considered, meaning the $(-1,1)$ interval. The differences outside this range shows a highly efficiency if the values are positive or a highly inefficiency if negative values appear.

Another problem was to estimate the speed of the convergence between the potential trade and the actual trade. For this, the following formula was used:

Speed of convergence $=$ Average growth rate of potential trade $/$ Average growth rate of actual trade $\times 100-100$ (the growth rate means the percentage change given the last year) 
The speed of convergence will be negative if the growth rate for actual trade will be bigger than the growth rate for potential trade. For analyzing the trade, the following matrix can be used:

Difference Difference

\begin{tabular}{|l|l|}
\hline Convergence & Divergence \\
\hline
\end{tabular}

Speed of convergence

Positive

\begin{tabular}{|l|l|}
\hline Divergence & Convergence \\
\hline
\end{tabular}

Speed of convergence

Negative

Positive Negative

Efficiency and convergence for Romanian trade flows in 2015 (author's own calculations)

\section{Convergence:}

Highly efficient flows: Algeria, Brazil, China, Cyprus, Germany, India, Italy, Japan, Korea, Montenegro, Morocco, Russia, Turkey, USA

Efficient flows: Austria, Belarus, Colombia, Czech Republic, France, Moldova Republic, Norway, Poland, Slovakia, South Africa, Spain, Thailand, Tunisia, United Kingdom

Inefficient flows: Angola, Croatia, Ghana, Kenya, Luxembourg, Madagascar, Mali, Panama, Paraguay, Philippines, Sudan, Switzerland, Tanzania, UAE, Uzbekistan

Highly inefficient flows: Antigua \& Barbuda, Armenia, Australia, Bahamas, Bahrain, Barbados, Belize, Benin, Bolivia, Botswana, Brunei Darussalam, Burkina Faso, Burundi, Cabo Verde, Cambodia, Cameroon, Canada, Central African Republic, Congo D.R., Costa Rica, Denmark, Dominica, Ecuador, El Salvador, Equatorial Guinea, Gabon, Guatemala, Guinea, Guinea-Bissau, Guyana, Haiti, Honduras, Hong Kong, China, Iceland, Jamaica, Kuwait, Lao P.D.R., Liberia, Macao, Maldives, Mauritius, Mongolia, Namibia, Nepal, New Zeeland, Nicaragua, Niger, Oman, Peru, Qatar, Rwanda, Saint Kitts and Nevis, Senegal, Seychelles, Singapore, Sri Lanka, Suriname, Tajikistan, Togo, Trinidad \& Tobago, Uruguay, Zambia 
Divergence:

Highly efficient flows: Bangladesh, Bosnia and Herzegovina, Egypt, Ethiopia, Georgia, Indonesia, Jordan, Kazakhstan, Lebanon, Macedonia, Mozambique, Nigeria, Pakistan, Sierra Leone, Swaziland, Vietnam

Efficient flows: Afghanistan, Albania, Azerbaijan, Fiji, Iraq, Libya, Malawi, Saudi Arabia, Tunisia, Turkmenistan, Uganda, Zimbabwe

Inefficient flows: Belgium, Côte d'Ivoire, Congo, Greece, Israel, Kyrgyzstan, Malaysia, Netherlands, Serbia, Slovenia, Ukraine

Highly inefficient flows: Bulgaria, Chile, Dominican Republic, Estonia, Finland, Hungary, Ireland, Latvia, Lithuania, Portugal, Sweden

The difference of trade (DT) and the speed of convergence (SC) were used to evaluate if there is convergence or divergence between actual trade and potential trade. If the speed of convergence is positive, it means that the growth rate of the actual trade is not as high as that registered by potential trade. If the speed of convergence is negative, it means that actual trade grows faster than the potential trade. When the actual trade grows faster (SC-) and the difference is positive $(\mathrm{DT}+)$, it means that the gap between AC (actual trade) and potential trade (PT) will widen so that divergence will appear. When the AC grows faster (SC-), although it is smaller than PT (DT-), it means that the gap between AC and PT will be narrowed, which suggests that a move in the direction of convergence took place. When AC grows slower than PT (SC+), but AC is smaller than PT (DT-), the gap between them will be widened; therefore, divergence had occurred. When AC grows slower than PT (SC+) and AC is bigger than PT (DT+), the gap will be narrowed and convergence between AC and PT takes place.

Although applied economists widely accept the gravity model and that our research results appear to be in line with those obtained by previous studies, we are perfectly aware of its limitations and the fact that trade flows are not "determined" by the variables taken into consideration. In the final analysis, all economic phenomena are the result of concrete human actions. The individual's choice is what determines GDP, the value of purchases from abroad and whether the transport of a particular good from afar is a wise decision. Aggregates like macroeconomic indicators, the degree of similarity between countries as indicated by the level of GDP per capita or population size, do not determine economic decisions in the same sense that the mass of the Earth determines an apple to fall to the ground. All that can be said is that individuals (may) take these things into account when they make up their minds about their next consumption or 
production decision. Therefore, we maintain that the results produced by our model should be interpreted with an appropriate dose of epistemological humility. Also, if policymakers were to make use of this model, they should be held to uphold the principle of "first, do no harm". Starting from this these qualifications, we maintain that policymakers can use the results of the gravity model as "a rule of thumb" for prioritizing their efforts. The recommendation of making wise use of public resources and application of the smallest possible tax burden have represented "good practices" since the day of Smith's Wealth of Nations. However, now, during our times of budget deficit and public debt limitations and resurfaced populist and protectionist rhetoric, Smith's counsel has become even more relevant. In this context, authorities should concentrate their limited resources on obtaining the best possible results, namely, they should concentrate their negotiation efforts and prioritize trade liberalization with those partner countries that offer the most promising perspective. A method for this could be to try to close the gap between actual and potential trade flows, as indicated by the model developed in this paper. Now, how we recommend that this endeavor should be pursued requires some justification of its own. We hold that the only policy that improves the welfare of all individuals (is Pareto optimal) and, at the same time, is simple enough to always work in practice (not only in the abstract models of economists) is a policy of free trade. Also, if we abstract from the possibility of international credit relations (which ultimately would have to be paid for through net exports), a country cannot operate above its potential trade level with all its partners. To put matters another way, the occurrence of trade flows above their potential is possible only if trade levels are under potential with other trade partners. Trade barriers or subsidies cannot push a country's trade beyond its potential. Overall trade levels cannot be forced à la longue. Even in the short run, the possibility of doing this is limited to two cases (limiting national consumption by decree and exporting the difference, or foreigners hoarding the currency of another country despite the increasing money supply) which likewise are quickly reversible. Hence, all that government interference with trade flows can do is to alter their structure and depress their volume, not increase it.

Accordingly, the ideal trade policy is one of free trade. Only such an approach can bring in line actual with potential trade flows. If Romania cannot adopt unilateral free trade because trade policy is a prerogative delegated to EU institutions, then the gravity model can be used as a political instrument in the following way:

- In the short run, policymakers should see if Romanian embassy personnel and trade associations can undertake any promotional activities in order to bring trade volumes closer to the benchmark provided by the gravity model.

- While, in the long run, they should identify any regulations that impede Romania's trade flows with a specific country and immediately modifying 
it, provided that such a decision is entirely in the hands of Romanian policymakers.

- Otherwise, if it is an EU specific issue, policymakers should bring the specific measure up for discussion in the relevant forum. Romanian policymakers should see in what cases trade levels are below their potential and begin their push for the liberalization of trade with those Conclusions countries at the appropriate EU level.

After presenting the findings and implications of the gravity model which figure in this paper, let us revisit the five research hypothesis and see how they hold up when faced with the results of our calculations.

The research hypothesis $\mathrm{H}_{1}$ (The economic size has a positive effect on trade flows), $\mathrm{H}_{2}$ (The similarity between countries in terms of GDPPC and population positively influences the trade flows) and $\mathrm{H}_{3}$ (The geographical distance between countries has a negative effect on trade flows) are fully supported. The hypothesis $\mathrm{H}_{4}$ (Sharing a common border, similar languages or economic membership have a positive effect on trade flows) is partially supported when it comes to the common border and the economic membership, while the Lang variable was rejected. $\mathrm{H}_{5}$ (The remoteness of partner countries has a negative influence on trade flows) is partially supported, as the ISLANDCOUNTRIES variable is rejected. Although the parameter of Lang dummy variable has the expected positive sign, it is not statistically significant. Similar languages between trade partners could be an indicator of similar cultures, showing consumer preferences for similar products and services. But the language used in negotiations is usually English, in this case a similar language having no influence over establishing a commercial relation from an operational point of view. As for the ISLANDCOUNTRIES dummy variable, the parameter has the expected negative sign, but, again, it is not statistically significant, because the trade with island countries does not hold a significant share in the trade flows. In the particular case of Romania, this country is placed at a high distance to any insular state. So, the parameter might be irrelevant when we already take into consideration the distance. Both the parameters for lndist and landlocked variables have the expected negative signs, although the one for the landlocked countries is greater than the one for distance, meaning the landlocked countries with which Romania engages in trade flows are mainly on other continents. This is surprisingly, because most of the countries which are surrounded by other countries on the same continent as Romania are also in the European Union. A possible explanation could be the poor road and railroad infrastructure of Romania. The Black Sea ports (especially Constanța) offer an important transportation alternative. A dummy which tests the trade relationship between Romania and other countries which have or have no 
access through their own ports to the Black Sea might have been relevant to a certain extent, or at least more relevant than the ocean access of the trade partner. The Border variable parameter has the highest value of all variables, reflecting an intense cross-border trade with neighboring countries. The results for dummy variables supported those of Aitken (1973) and Sapir (1981).The parameter for lndist is slightly smaller than expected because most of Romania's trade is with countries from Europe and, therefore, the distances are not too large. The coefficients for distance are lower than in Head (2003).The parameters for EU and Schengen dummy variables have the expected positive signs, proving that Romania's EU membership brings with it a strong positive influence. The difference between the two values is explained by the fact that Romania is not a Schengen member yet. An interesting case here is the situation of UK. The trade flows between Romania and UK are still very intense because UK is still an EU member until 2019. Further research should be conducted in order to find out if trade flows between Romania and UK suffered after Brexit.The efficiency and the convergence of the Romanian trade flows were assessed using the difference between actual and potential trade flows and the speed of convergence. To analyze the design of the Romanian trade flows between 2001 and 2015, we introduced and tested two new explanatory variables, Simcap and Simpop, variables which captures the similarities between two countries regarding the GDP per capita and the populations of the two countries. Both similarity variables produce a strong positive influence on trade flows and so does the GDPT, which is the sum of GDP per capita of Romania and the partner country, this variable has the most significant influence of all three. The coefficients for the total GDP per capita are in line with Rose et al. (2000), those for Simcap and Simpop are slightly above in line with Feenstra (2002). The model we proposed is an extension of the one proposed by Egger in 1999. The five research hypotheses were fully supported by the empirical results for the main variables and partially supported for the dummy variables. The results are robust and consistent with the previous studies.

Limits of the model:

This model does not specifically take into account patterns of specialization. This could explain why we have surprisingly results regarding examples of trade relationships between Romania and countries like Bulgaria and Hungary, which were classified as highly inefficient, meaning that the bilateral trade is below its potential. Perhaps trade between these countries is lower than one might expect because the goods they produce are designed for markets other than each other's. Referring to the size of the population, we include in the model the number of people with a certain permanent residence, ignoring migration. That means that a certain part of exports and imports is influenced by where people work (produce) and live (consume). So, part of the results might be distorted by the 
number of people who are registered and actually live in different places. And for countries like Romania, this number is significant. Nevertheless, people do not entirely consume in the countries they live in. Remittances from citizens working abroad to Romania are also large, fact that helps us to justify the results we obtained. The model doesn't include any connection to the historical / traditional trade relationships which Romania used to have with certain countries in the communist era, some of them being preserved even after the trade diversions which took place when Romania acceded the European Union. That means Romania still registers important trade flows with certain countries, continuing traditional relations. The bilateral relation Romania still develops is of equal importance. Despite the statistical robustness of our results, we hold that the gravity model should be used prudently by policymakers. We consider that the best use of these results is to aid decision makers in prioritizing the dismantlement of the obstacles that keep trade flows from being in harmony with their potential values. As we explained, the only feasible solution for obtaining an efficient outcome for Romania is to liberalize trade as fast as possible and to prioritize this endeavor by starting this drive toward freer trade with those countries for which the trade flows are situated furthest below from the values predicted by our model.

\section{REFERENCES}

[1] Aitken, N.D. (1973), The Effect of EEC and EFTA on European Trade: A Temporal Cross-Section Analysis; American Economic Review, 63 (4): 881-892; [2] Anderson, J. E. (1979), A Theoretical Foundation for the Gravity Equation; American Economic Review, 69: 106-116;

[3] Anderson, J.E. (2011),The Gravity Model;Annual Review of Economics, 3: 133-160.https://doi.org/10.1146/annurev-economics-111809-125114;

[4] Baldwin R. \&Taglioni, D. (2006),Gravity for Dummies and Dummies for Gravity Equations; NBER Working Paper $N^{\circ}$ 12516, September.

[5] Baldwin, R. \& Taglioni, D. (2010), Gravity Chains: Estimating Bilateral

Trade Flows when Parts and Components Trade is Important, available at: www.nber.org/papers/w16672, last accessed 11.12.2015;

[6] Bergstrand, J. H. (1985), The Gravity Equation in International Trade: Some Microeconomic Foundations and Empirical Evidence; The Review of Economics and Statistics, 67: 474-481. DOI: 10.2307/1925976;

[7]Blum B.S. \& Goldfarb A. (2006),Does the Internet Defy the Law of Gravity?; $J$ Int Econ, 70 (2): 384-405;

[8] Egger, P. (1999),A Note on the Proper Econometric Specification of the

Gravity Equation; Economics Letters, 66 (2000): 25-31; 
[9] Egger, P. (2002), An Econometric View on the Estimation of Gravity Models and the Calculation of trade Potentials; World Economy,25 (2): 297-312. https://doi.org/10.1111/1467-9701.00432;

[10] Evenett, S. and Keller, W. (2002), On Theories Explaining the Gravity Equation; Journal of Political Economy, 110: 281-316. (DOI): 10.3386/w6529; [11] Feenstra, R.C., (2002),Border Effects and the Gravity Equation: Consistent Methods for Estimation; Scottish Journal of Political Economy, 49 (5): 491506.https://doi.org/10.1111/1467-9485.00244;

[12] Fidrmuc, J. (2009), Gravity Models in Integrated Panels;Empir Econ, 37: 435-446;

[13] Head, K. (2003), Gravity for Beginners, available at: https://www.google.ro/?gws_rd=cr,ssl\&ei=hduHVordNsXIyAP_4bSAAQ\#q=Hea $\mathrm{d} \% 2 \mathrm{C}+\mathrm{K} .+\% 282003 \% 29 \% 2 \mathrm{C}+\% \mathrm{E} 2 \% 80 \% 9 \mathrm{CGravity}+$ for +beginners\%E2\%80\%9 D\%2C+mimeo\%2C+University+of+British+Columbia, last accessed 14.12.2015; [14] Linneman, H. (1966), An Econometric Study of International Trade Flows. Dissertation; Netherlands School of Economics, Amsterdam;

[15] Mátyás, L. (1997), Proper Econometric Specification of the Gravity Model;The World Economy, 20 (3): 363-368. https://doi.org/10.1111/14679701.00074;

[16] Rose, A. K., Lockwood, B. and Quah, D. (2000), One Money, One Market: The Effect of Common Currencies on Trade; Economic Policy, 15 (30): 7-45;

[17] Santos Silva, J. and Tenreyro, S. (2006), The Log of Gravity; The Review of Economics and Statistics, 88: 641-58;

[18] Sapir, A. (1981),Trade Benefits under the EEC Generalized System of Preferences; European Economic Review, 15: 339-355. https://doi.org/10.1016/S0014-2921(81)80006-2;

[19] Tinbergen, J. (1962), Shaping the World Economy; Suggestions for an International Economic Policy;Books (Jan Tinbergen); Twentieth Century Fund, New York;

[20] www.chemical-ecology.net, last accessed 04.12.2015;

[21] www.data.worldbank.org, last accessed 04.12.2015;

[22] www.econweb.rutgers.edu, last accessed 04.12.2015;

[23] http://encyclopedia2.thefreedictionary.com/, last accessed 10.12.2015;

[24] www.hdr.undp.org/en/data, last accessed 10.12.2015;

[25] www.trademap.org, last accessed 22.12.2015. 